The evolutionary origin of the Pithecanthropus group is entirely conjectural. Presumably it is derived from a dryopithecine ancestry ; but here there is a conspicuous gap in the palæontological record.

In the classical examples of Neanderthal man, the skeleton shows the development of a number of somewhat specialized characters from which it is inferred that the type could scarcely have given rise to Homo sapiens. As no transition types of later date have been found, it is legitimate to assume that Neanderthal man became extinct. It is significant that typical Neanderthal forms belong to the later phase of the period, whereas the remains belonging to the earlier part of the Mousterian epoch, such as, for example, those found at Krapina in Croatia, are less typically Neanderthaloid. This agrees with the occurrence of pre-Mousterian types (for example, Ehringsdorf, Steinheim, Swanscombe) which show a close resemblance to Homo sapiens. There can be little doubt that they were the precursors of modern man.

The Pithecanthropus group then almost certainly provided the basis for the development of later types of man. Of these, one is represented by the rather specialized Neanderthal type of later Mousterian date - an aberrant line--and a second by types of early Mousterian and pre-Mousterian date which were less distinctively Neanderthaloid and more akin in their anatomical features to Homo sapiens.

\title{
DEVELOPMENTS IN ELECTRIC SURGE RECORDING
}

$I^{N}$ 1933 a considerable amount of investigation had already taken place, chiefly outside Great Britain, with the view of determining, by means of special devices called klydonographs, the effects of lightning discharges upon overhead lines. The klydonograph is an instrument in which an electric discharge takes place on to a photographic plate or film, the resulting impression affording a record of the characteristics of the discharge. The advent of the National Grid in Great Britain stimulated interest in the subject. Whilst it was seen that the published information from various countries could be usefully applied, it was also realized that, as the results were dependent on so many variables, this needed great care, and that a similar and independent investigation could with advantage be carried out in Britain.

This was undertaken by the British Electrical and Allied Industries Research Association, with the co-operation of the Central Electricity Board and the Yorkshire Electric Power Company. The complete investigation included the use of a high-voltage cathode ray oscillograph and magnetic links in addition in continuously recording klydonographs, but only the last mentioned are to be considered here. It was agreed that these instruments could not be regarded as accurate peak surge voltmeters, but that they were capable of indicating the approximate magnitudes, polarities and times of occurrence of voltage surges.

The investigation was begun in 1933 , on an $11 \mathrm{kv}$. line owned by the Yorkshire Electric Power Co. Three klydonographs were coupled to the line by means of concentric-cylinder type capacitance 'potential-dividers'. It was soon found out that the klydonographs were not suitable for unattended use, and new ones containing many improvements were developed. Progressive elimination of defects resulted in trustworthy and satisfactory operation by May 1937, since when no noteworthy trouble has been experienced.

On April 5 J. L. Candler read a paper before the Institution of Electrical Engineers on developments in surge recording by means of the klydonograph. This paper is based on the E.R.A. report Ref. S/T 26, and is mainly concerned with the instruments and their auxiliaries. The principle of operation of the klydonograph is fairly simple. A high-voltage electrode is placed in front of and touching a photographic film. The momentary application of a high voltage across the electrode will produce a distinctive figure on the film after development. This figure is known as a photographic Lichtenburg figure or klydonogram, and from its size and type certain features of the voltage causing it can be deduced. By causing the film to slide between the electrodes at a known rate, the time of occurrence of the surge can be estimated. Generally two films and two pairs of electrodes are used. By comparing the two concurrent figures the polarity of the voltage producing them is definitely determined.

The complete instrument consists essentially of three parts : (1) a light-proof box containing the spools of unused films, the electrode system and the feed-control sprocket wheels; (2) a smaller lightproof box, containing spools on to which the used film is wound; and (3) a compartment containing two clock-work motors. Hundred foot reels of $35 \mathrm{~mm}$. film are used and the travel rate is 1 inch an hour. Thus the films last for about seven weeks, but provision is made for cutting off the used film when desired, and two interchangeable take-up boxes are provided for each instrument.

In the latest type many improvements have been introduced and little trouble is now experienced. It is essential that in making tests on klydonographs the conditions should stimulate practical conditions as nearly as possible. For this reason a test hut was erected in the field behind the laboratory building. The requisite voltage is applied by a transformer either directly or through the potential divider. Experience since 1937 indicates that mechanically the devices have attained a very high standard of perfection, and that electrically the performance cannot be improved further with this type of instrument.

No surges considered to be due to lightning were recorded on the Rayleigh-Southend line, on the lines in South Scotland or at the (G.E.B.) Creekmouth transforming station. Recording on the RotherhamDoncaster line and the Thornhill-Barugh line each yielded fifteen. Surges due to switching were numerous, but they are usually uni-directional and are approximately equally divided between the two polarities and limited to not more than twice the normal voltage. 